\title{
Ensayo sobre la Melancolía
}

\section{Melancholia: an Essay}

\author{
Marta Chacón Salinas ${ }^{1}$ \\ Universidad Santo Tomás de Chile
}

(Recepción: Octubre 2005-Aceptación: Noviembre 2005)

\begin{abstract}
Este trabajo es un intento de delimitar la melancolía del conjunto de los trastornos depresivos y de reflexionar sobre sus características tal como aparecen en el discurso de los melancólicos. Se consideran algunas hipótesis en la línea psicoanalítica freudiana y lacaniana (Lambotte, Kristeva) para entender cómo se va constituyendo en sus características principales: la intolerancia a la pérdida del objeto y el desfallecimiento del símbolo que le impide elaborar este duelo.
\end{abstract}

Palabras clave: Melancolía, discurso, depresión mayor.

This paper attempts to differentiate melancholia from other depressive disorders and to reflect on its characteristics as described by melancholics. We look at some hypotheses in Freudian and Lacanian psychoanalysis (Lambotte, Kristeva) to understand how its main characteristics develop: intolerance to loss and the weakness of symbols that enable the sufferer to go through the grieving process.

Key words: Melancholia, discourse, depression

\section{Introducción}

Conocer quién es el o la melancólico/a y cómo se ha ido constituyendo es lo que me interesa explorar en este trabajo. A medida que avance en esta exploración señalaré algunas semejanzas o diferencias con la organización limítrofe y procuraré aludir al contexto cultural posmoderno en el cual vive el depresivo-melancólico actual.

Cómo se ubica la melancolía en el conjunto psicopatológico:

1. Lo que Freud, Lambotte y Kristeva describen como un cuadro melancólico corresponde en la nomenclatura del DSM IV, al Trastorno depresivo mayor (recidivante o crónico) o al Trastorno bipolar II, depresivo, aunque no siempre se detecta la existencia de un episodio hipomaníaco.

2. Melanie Klein diferencia entre posición esquizo-paranoídea y depresiva, y considera a esta última como un paso de mayor desarrollo en el establecimiento de relaciones objetales y, consecuentemente, en la estructuración del sujeto.

Una pregunta general antes de partir con esta reflexión: ¿Por qué el/la melancólico/a responde favorablemente a la acción de antidepresivos si todo el desarrollo del pensamiento psicoanalítico lo muestra enraizado en la dinámica de la relación

Psicóloga, Licenciada en Psicología, Pontificia Univeridad Católica de Chile. Magíster (c) en Psicología, Pontificia Universidad Católica de Chile. E-mail: mchacon@santotomas.cl madre-hijo/a? ¿Es genético este enclave biológico de la melancolía o se desarrolla como un equivalente somático de la angustia de no ser mirado, de no existir en el mundo vivencial de la madre?

Intriga el adjetivo "ogresa" que usa Lambotte (1996) para referirse a esta madre que tal vez, más atenta a sí misma que al niño o abiertamente rechazadora de él, no lo refleja en su mirada, no lo inviste libidinalmente como objeto de deseo, y de esta manera, no le permite apropiarse de su propia imagen. Esta alusión a la devoración que incluye el adjetivo tiene en el melancólico un sentido distinto a la angustia de inclusión del limítrofe, que hemos definido como una que surge del exceso, de la vivencia de ser un objeto de deseo tan intenso para la madre que advertir esto despierta en el niño la angustia de ser devorado. En el melancólico, en cambio, la angustia de inclusión o devoración viene de la falta, su miedo sería a ser devorado por la nada.

En "La historia interminable" de Michael Ende, ocurre que el Reino de la Fantasía (lo Imaginario) va siendo devorado por la Nada, que se apropia de espacios y seres vivos, y se puede entender de esta forma el adjetivo adscrito a la madre. A partir de aquí, sentir el límite se vuelve vital para el melancólico, sentirlo en el cansancio del cuerpo, en el dolor auto-infligido, en el borramiento que casi la o lo hace desaparecer; que pueda sentir este límite es testimonio de que todavía existe, de que no ha sido hecho desaparecer por esta Nada que lo envuelve desde la no-mirada de la madre. 
Así, descubro al melancólico como un sobreviviente diario de la nada. ¿Tal vez por eso se alivia por las tardes, porque otro día más no cedió a la tentación de hundirse en ella, suicidándose? Y también lo descubro como el más claro exponente de la "angustia existencial" de la época moderna o de la necesidad, no sólo ni exclusivamente romántica, de encontrarle un sentido a la propia existencia.

'Desde aquí es posible entender su agobio, su cansancio extremo... porque todo es paroxístico en el/la melancólico/a. Sentimos, estando en su cercanía, que él libra una batalla en el campo de lucha en que lo vivo se diferencia de lo inerte, en el campo en que las palabras no alcanzan a nombrar los movimientos de fuerzas que sostienen la existencia entre el ser y la nada. Y por eso nos parecen tan sabias y profundas sus afirmaciones, porque las trae desde el subsuelo donde se libran estas batallas.

Un melancólico ya no quiere leer más nada que no sea filosofía o religión, porque otra literatura le parece pérdida de tiempo y de la escasa energía de que dispone. ¿Es en la trascendencia hacia atrás, hacia el magma de lo no vivo todavía, desde donde se rescata cada mañana para arrastrarse ese día hasta que se pone el sol?

En lo siguiente, se aborda la delimitación del cuadro melancólico siguiendo a varios autores: a Freud para separarlo del duelo, a Lambotte para diferenciarlo de la depresión (neurótica) y a Kristeva para incursionar cada vez más cerca de la vivencia, en los elementos comunes del conjunto melancólico-depresivo, en particular en el desfallecimiento del significante. Por último se consulta a estos y otros autores para encontrar los elementos comunes y los distintivos con respecto a la organización limítrofe.

\section{Desarrollo}

Duelo y melancolía, dice Freud (1915), comparten las mismas serias perturbaciones: una desazón interna profundamente dolida, la cancelación de todo interés por el mundo, la inhibición de toda productividad y la pérdida, transitoria en el mejor de los casos, de la capacidad de amar. Sin embargo, a nadie se le ocurriría considerar patológico el duelo porque al observador le es evidente su causa.

Parte de lo que nos hace tan incomprensible y a veces irritante al melancólico es que no logra- moś encontrar un acontecimiento próximo o distal en su historia que lo haya hecho entrar en este estado: "Yo soy así, triste, reconcentrado... nací así... deben ser los genes", decía un paciente.

Podríamos decir que el melancólico está permanentemente de duelo, pero no sabemos, y él tampoco, qué o quién se le ha muerto, y cuando se trata de una pérdida amorosa tampoco él sabe exactamente qué es lo que ha perdido o qué se ha muerto en él al perder al amado/a. Se trataría entonces, dice Freud, de una pérdida sustraída a la conciencia, lo que no ocurre en el duelo.

Es este un primer elemento diferenciador entre ambos cuadros, al que se agrega otro, una perturbación en el sentimiento de sí que se expresa en auto-reproches y denigraciones de sí mismo. A veces el duelo tiene una expresión parecida; la persona se culpa de no haber retenido al otro para que no se expusiera a un riesgo o de no haber estado allí para evitar su accidente; son auto-reproches por una supuesta responsabilidad en su muerte. Sin embargo, esta culpa no toca al sentimiento de sí como un todo: la persona puede resultar culpable ante sí por ello, pero no denigrada.

En la melancolía, en cambio, el sí mismo resulta rebajado. No es el mundo el que se ha vuelto pobre y vacío sin la presencia del otro, es el yo el que se ha empobrecido y se ha vuelto "indigno, estéril y moralmente despreciable" (Freud, 1915, pp. 240). Es un delirio de insignificancia, una insuficiencia radical que aparece en el sentimiento del depresivo posmoderno.

A veces, en este enjuiciamiento implacable se acerca con extrema lucidez a sus reales características, otras veces no hay correspondencia ninguna con ellas. Si uno escucha con persistencia, dice Freud, advierte que estas denigraciones se ajustan más a otra persona, aquella que el melancólico ama o ha amado. Son autoreproches revertidos, reproches contra un objeto de amor que desde éste han rebotado sobre el yo. Su ánimo es de revuelta, sus quejas son querellas, todo lo rebajante que dice de sí, en el fondo, lo dice del otro. En una formulación simplista se podría decir que el melancólico es un furioso que no se atreve a usar su furia contra el objeto que ama o que amó.

Freud hace una descripción de este proceso y adelanta una hipótesis: "Hubo una elección de objeto, una ligadura de la libido a una persona determinada. Por obra de una afrenta real o 
un desengaño de parte de esta persona, sobrevino un sacudimiento de este vínculo. La investidura libidinal del objeto resultó poco resistente y fue cancelada, pero la libido libre no se desplazó a otro objeto sino que se retiró sobre el yo y allí sirvió para establecer una identificación del yo con el objeto (ahora) resignado (negativamente). La sombra del objeto cayó sobre el yo, que en lo sucesivo pudo ser juzgado por la conciencia moral como el objeto abandonado. De esta manera, la pérdida del objeto se mudó en una pérdida del yo, y el conflicto entre el yo y la persona amada, en una bipartición entre el yo crítico y el yo alterado por la identificación". (Freud 1915, pp.246-247).

A partir de aquí veo que el conflicto que hubiera podido ser externo, en el odio y rechazo a esta persona, se internalizó; un ejemplo que puede servir a la tesis de que en las sociedades posmodernas es posible que el conflicto no haya desaparecido (Erhenberg 2000) sino que se haya sumergido; y esto, aunque disminuye las probabilidades de enfrentamientos bélicos, no necesariamente es mejor para los individuos.

¿Por qué la investidura fue tan poco resistente si la fijación al objeto era tan intensa? Para entenderlo, Freud supone que la elección de objeto se ha realizado sobre una base narcisista, es decir, que hubo una identificación narcisista con el objeto en vez de una investidura de amor. Y aclara: "la identificación es el primer modo como el yo distingue al objeto y es la etapa previa a la elección de él, el yo querría incorporárselo en verdad, por vía de la devoración". Su hipótesis es que en todo o, al menos en parte, la disposición a contraer melancolía se debe al predominio de una elección narcisista del objeto. Si esto se corroborara con la observación, podría decirse que, ante la afrenta real o el desengaño de la persona amada, el melancólico regresa desde la investidura del objeto hasta la fase oral de la libido, que es todavía narcisista.

Ochenta años después Lambotte (1996) se refiere a la elección narcisista del objeto para explicar la intensidad y fragilidad del vínculo amoroso en el melancólico, al que ve estableciendo una relación de demanda absoluta con el objeto, que resulta instalado en el lugar del ideal del yo. Esta exigencia imposible de cumplir asegura su desengaño y confirma su desesperanza: yo lo sabía, sólo podía terminar de esta manera, de nuevo he sido traicionado, es siempre la misma cosa" (pp. 8).
Atendiendo al discurso de sus pacientes depresivos, Lambotte distingue dos organizaciones diferentes, el depresivo neurótico y el melancólico, y examina ambas en función de cómo se refieren al cuerpo, a la imagen de sí, a si hay o no un punto de inicio de la enfermedad y, desde el punto de vista clínico, a si existe o no la posibilidad de instaurar una relación transferencial. Como corresponde a un neurótico, con el depresivo es posible establecerla; en cambio, con el melancólico es difícil, si bien no imposible como ocurre con las psicosis.

La dificultad de instaurar una relación transferencial aparece desde que el melancólico llega a la consulta, más bien traído que por propia voluntad, dispuesto a dejarse entrevistar pero sin esperanza de ser ayudado, sin demanda de ayuda. Es como si dijera "Ud. puede hacer su tarea conmigo pero eso no va a hacer diferencia en la forma como me siento". Incluso el hablar para él ha perdido sentido, porque las palabras se han descargado de sus significados; a ratos pareciera que está en retroceso al mutismo anterior a la instauración del lenguaje. Kristeva tendrá luego palabras para fundamentar esta observación.

Otro aspecto en su discurso que lo diferencia del depresivo es que no fija un punto de comienzo para su enfermedad, que parece que siempre hubiera estado allí, en el trasfondo, reactivándose cada cierto tiempo con estímulos, algunos relacionados con pérdidas y otros que difícilmente pueden relacionarse con ellas. $\mathrm{He}$ podido advertir con pacientes que la afrenta del ser amado de la que habla Freud puede no hacerlo reaccionar, pero va aletargándolo en un nivel de escasa reactividad e iniciativa en la acción, sin que él perciba claramente qué le ha quitado el impulso vital.

El melancólico se refiere al cuerpo como "este cuerpo", ajeno a él, vivido como una exterioridad. Una paciente melancólica "lo empuja" como algo que no le perteneciera, pero en momentos de intensa agitación es a través del agotamiento de errar a la deriva que logra obtener algún alivio de la angustia, recién allí "por el cansancio siento por fin mi propio cuerpo". La anestesia corporal puede estar contribuyendo al sentimiento de vacío que el melancólico experimenta y que expresa como "estoy vacío", distinto a la expresión "me siento vacío" del deprimido.

Así también la imagen de sí, que en el depresivo está desvalorizada, falta por completo en el discurso del melancólico. En cambio, sí 
aparece la mirada, como si sólo pudiera verse desde la mirada de otro, mirada cargada de intención que inviste al objeto.

¿Es que se siente existiendo sólo si es mirado? si no, ¿es invisible?, ¿no tiene presencia?, ¿no existe? No es una situación muy distinta a la que se experimenta cuando se está en un país extranjero cuya lengua no se conoce. Inicialmente se es mirada, pero luego los otros rehuyen el contacto visual para no estar obligados a dirigirle palabras que la persona no entenderá. Puedo imaginar que si esta situación se prolongara, el sentido de identidad estaría en riesgo. ¿Cuándo puede haberle pasado algo así al melancólico?, ¿por qué no ha podido apropiarse de su propia imagen?

Lambotte remite a la experiencia del espejo en la primera infancia, que sirve para explicar sucesivas identificaciones que llevan a la adquisición de una imagen. La primera identificación es con el rostro del que nos cuida, el representante de la especie. El bebé es uno con este rostro y sólo muy posteriormente, puesto frente a un espejo, advierte que aquel que se refleja en él no es otro niño sino él mismo. La experiencia especular en sus dos etapas es entonces la base para la formación de la imagen de sí.

Lambotte se explica la falta de imagen de sí en el discurso del melancólico como resultado de una insuficiencia especular, una escasa identificación al reflejo en el espejo. Su hipótesis es que el melancólico se habría quedado identificado con el rostro de la madre sin pasar a la segunda identificación, debido a que el rostro de la madre "es lo que lo sostiene" y le impide ser arrastrado hacia la fragmentación esquizofrénica.

Kristeva se acerca a la depresión desde adentro con tal intensidad del lenguaje que nos hipersensibiliza ante el que la sufre. En la depresión, dice, "el sin sentido de mi existencia me parece evidente, deslumbrante" y se pregunta " $i$ de dónde viene ese sol negro que me clava a la cama, al mutismo, a la renuncia?" Abandonado de los dioses el depresivo, este desesperado fue condenado a la ausencia, al vacío, al alejamiento.

Los dos términos, melancolía y depresión, designan un conjunto que va desde la tristeza pasajera pasando por el duelo hasta el estupor melancólico. En este conjunto "melancólicodepresivo" las fronteras se difuminan, si bien la psiquiatría reserva el término melancolía para la enfermedad irreversible que sólo cede con antidepresivos. Situada en un perspectiva freudiana, la autora realza lo común en todos estos estados. la intolerancia a la pérdida del objeto y el desfallecimiento del significante.

Conviene entender a qué se refiere con esta segunda expresión. El punto de partida para hablar de significante son las representaciones de afecto, pero ahora la pregunta es ¿cómo se llega a los signos desde esta arcaica inscripción de los acontecimientos internos y externos que se supone es el afecto?

La autora sigue la hipótesis de Hanna Segal (1957, en Kristeva,1994), según la cual a partir de una separación, el niño produce o utiliza objetos o vocalizaciones que son equivalentes simbólicos de lo que falta. Más tarde y una vez instalado el sujeto en la posición depresiva, intenta manifestar la tristeza que lo abruma produciendo en su propio yo elementos extraños al mundo exterior que hace corresponder a esa exterioridad perdida o descentrada: estamos pues en presencia de símbolos.

Kristeva (1994) completa este desarrollo agregando otros pasos: la capacidad del yo para identificarse con una tercera instancia-padre, lo cual asegura su entrada en el universo de los signos y de la creación; y luego el imperativo de que ese padre de la prehistoria individual pueda asegurar su papel de padre edípico, porque "si se unen armoniosamente estas dos caras de la paternidad, los signos abstractos y arbitrarios de la comunicación tendrán la suerte de ligarse al sentido afectivo de las identificaciones prehistóricas, y así el lenguaje muerto (por no ligado) del depresivo en potencia podrá obtener un sentido vivo en el nexo con los otros" (p. 27).

Me parece ésta una magistral descripción de la forma como se llega al signo partiendo del afecto. Queda ahora por observar cuáles indispensables condiciones tienen que darse para que los símbolos adquieran vida y no desfallezcan. Lo primero es que tiene que haber una ausencia, una separación de la madre o primer cuidador/a del niño; lo segundo es que para identificarse con una tercera instancia es necesario que ésta exista y, luego, que cuando la madre o cuidadora esté presente le haga espacio frente al niño (o será suficiente que sólo lo nombre?); tercero, que el padre primordial y el edípico formen un todo armónico y, cuarto, un elemento que pocas veces aparece en las comunicaciones 
especializadas, la presencia azarosa de la suerte. Además, la autora se encarga de enfatizar la función del padre como guía para representar esta ausencia, constelación que falta en la organización limítrofe.

En un capítulo dedicado a Biología y Lenguaje, Kristeva (1993) se refiere a los adelantos actuales de la neurobiología y farmacología, y sostiene que ellos no inhabilitan al psicoanálisis sino que invitan a reactualizar la noción freudiana de pulsión, bisagra entre el soma y la psique, entre la biología y la representación.

No puedo menos que imaginar a los melancólicos que conozco, casi sin aparente pulsión que los dirija hacia objetos actuales y con una presencia silenciosa que es casi no vista por quienes los rodean. No es que no haya pulsión alguna, puede haber una que los conduzca hacia atrás, hacia los objetos originarios y más atrás, hacia lo que llamé al principio el magma vivo del que se desprenden los objetos, hasta casi tocar la muerte.

Con respecto a la pulsión, no hay que olvidar, dice Kristeva (1993), que la estructura del sujeto se construye con las diferentes posiciones del yo respecto a las distintas modalidades del objeto que se forman en el intervalo que va de la pulsión al lenguaje. Esta estructura subjetiva está cargada con el destino de las pulsiones y su doble naturaleza, biológica y representacional. Y continúa: "Por ejemplo la fantasía, que podemos entender como el resultado de la irrupción de la pulsión en la lógica serena del pensamiento (...), viene a recordarnos que la pulsión, y por derivación el afecto, es un factor de organización y permanencia que modula la actividad del pensar (es decir) del razonamiento y la palabra" (p. 38).

Todo esta referencia teórica sirve de base para analizar la imbricación pulsión/lenguaje en el habla desvitalizada del deprimido. La depresión desautoriza el sentido del discurso, que es llevar Eros hacia el objeto, y la pulsión de muerte hace imposible la separación del yo y del objeto.

Según la teoría psicoanalítica clásica (Kristeva, 1996), la depresión oculta, como ya lo hemos dicho antes, una agresividad contra el objeto perdido y revela así la ambivalencia amor-odio hacia él. "Lo amo, parece decir el depresivo, pero aún más lo odio; porque lo amo para no perderlo lo instalo en mí; porque lo odio, este otro en mí es un yo malo, soy malo, soy nulo, me mato". La queja contra sí mismo es entonces una queja contra el otro y la ejecución del suicidio, un disfraz trágico de su masacre.

Kristeva (1994) se pregunta si esta retracción masoquista del odio apuntará a un odio más arcaico, a una pulsión de muerte como Freud sostiene. No sólo en el masoquismo sino en varias patologías de la infancia (mericismo, algunos autismos, anorexias) se asoma esta pulsión que "apareciendo como una ineptitud biológica y lógica para trasmitir las energías y las inscripciones psíquicas, destruye circulaciones y nexos" (p. 21).

La inhibición melancólica puede considerarse una manifestación de esta desintegración de los nexos. El humor depresivo, en cambio, la tristeza, reconstruye una cohesión afectiva y se constituye en un soporte narcisista, negativo es cierto, pero capaz de ofrecer al yo una integridad. Por ello puede considerarse la tristeza como una defensa contra el despedazamiento del yo, que en el depresivo es literalmente un caer a pedazos.

Sin embargo, esta defensa es una protección frágil y si no tiene la suerte de apoyarse en cierta erotización del sufrimiento no funciona frente a la pulsión de muerte. Por otra parte, el sujeto hablante puede reaccionar también contra los sinsabores con inhibición-lentitud, negando la secuencialidad y neutralizando el significante (el "eso no tiene sentido" del melancólico). Si el estado no-depresivo es la capacidad de concatenar, el depresivo ya no concatena y, en consecuencia, no actúa ni habla.

Uno de los modelos que se ha propuesto para explicar la lentitud depresiva es el de la desesperanza aprendida, según el cual la inacción constituiría una reacción aprendida de defensa contra una situación sin salida. Los antidepresivos tricíclicos restauran la capacidad de fuga, lo que los hace tan efectivos cuando es la inhibición y no la tristeza lo que caracteriza el cuadro.

Llegados a este punto en el esfuerzo por concebir las dos vías de la depresión, la psíquica y la biológica, conviene traer a cuento, dice Kristeva, el asunto de la importancia del lenguaje para los seres humanos. Contrariamente al animal, el niño puede encontrar una solución de lucha o fuga en la representación psíquica y en el lenguaje. Imagina, piensa, habla la fuga o la lucha, lo que evita que se repliegue en la inacción o en el hacerse el muerto. Para que pueda elaborar esta solución no depresiva, le hace 
falta una sólida implicación en el código simbólico e imaginario, que solo de esta forma se convierte en estimulación y refuerzo. Si la estimulación simbólica resulta insuficiente, el sujeto se vuelve a encontrar en la situación sin salida de la desesperanza aprendida. En otras palabras, el lenguaje es un poderoso factor que por mediaciones todavía desconocidas ejerce un efecto de activación sobre los circuitos neurobiológicos.

¿Es el desfallecimiento simbólico del depresivo una expresión más de la pérdida de velocidad que se observa en él o es una precondición esencial de ella? ¿Está condicionado por el mal funcionamiento de los circuitos neuronal y endocrino que sirven de base a las representaciones de palabras, o es una insuficiencia de implicación en el código simbólico causado por el entorno familiar o social?

Estas preguntas de Kristeva guardan alguna relación con la pregunta amplia que formulé al comienzo, ¿por qué el melancólico responde favorablemente a la acción de antidepresivos si todo el desarrollo del pensamiento psicoanalítico muestra esta afección enraizada predominantemente en las experiencias (familiares) tempranas?

En este recorrido de autores me queda claro, sin embargo, que no se trata de elegir entre una u otra de las explicaciones, sino abordar ambas vías, la biológica y la psicológica.

\section{Conclusión}

El discurso del melancólico da cuenta de grandes ausentes: no hay vivencia del cuerpo, no hay apropiación del espacio personal, no hay conciencia de lo perdido, no se ha apropiado de una imagen de sí; el tercero (el padre) puede no haberlo conectado poderosamente con el universo simbólico.

Hay muchos aspectos que están presentes en la vivencia normal y que el melancólico no ha podido incorporar a partir del vínculo primordial con la madre, o bien que ha seguido perdiendo al avanzar en sus desengaños. Significa esto un retroceso en la individuación, un no poder hacer pie en sí mismo.

También al melancólico desvitalizado le falta la palabra. Su experiencia de vacío, de un self vacío, en parte proviene de un vacío representacional: no tiene nada que decir "que valga la pena" (insuficiencia depresiva) y ya sabemos que la participación en conversaciones confirma (o desconfirma) al self. Se trata de una depresión primaria o blanca, de un estado afectivo neutro, sin sufrir, sin dolor, paradójicamente semejante a la descripción del hombre cool posmoderno, que no experimenta sufrimiento y que trivializa el lenguaje, es decir, usa y recibe palabras que están desinvestidas de significado.

\section{Referencias}

BERGERET, J., 1996. Cap. 4 Las a-estructuraciones. En "La personalidad normal y patológica". Gedisa, Barcelona.

FREUD, S., 1915. Duelo y melancolía. En Tomo XIV de Obras completas Ed. Amorrotu.

KERNBERG, O., 1979. Desórdenes fronterizos y narcisismo patológico. Paidós, Barcelona.

KRISTEVA, J., 1995. Las nuevas enfermedades del alma. Ed. Cátedra. Madrid, España.

KRISTEVA, J., 1997. Sol negro. Depresión y melancolía. Monteavila Editores Latinoamericana, Caracas.

LAMBOTTE, M. C., 1996. El tema de lo especular y de los bordes en la melancolía. Traducción M.González de Conferencia publicada en "Le Bulletin Freudien" $\mathrm{N}^{\circ} 27$, Bélgica.

EHRENBERG, A., 2000. La fatiga de ser uno mismo. Depresión y sociedad. Ed. Nueva Visión, Buenos Aires. 